\title{
Evidence for Two Classes of Nociceptive Modulating Neurons in the Periaqueductal Gray
}

\author{
Mary M. Heinricher, Zhen-feng Cheng, a and Howard L. Fields \\ Departments of Physiology and Neurology, University of California at San Francisco, San Francisco, California 94143
}

The midbrain periaqueductal gray (PAG) and the rostral ventromedial medulla (RVM) are important links in a neuronal network that modulates nociceptive transmission. In the RVM, 2 classes of cells have been identified that show changes in activity at the time of the tail-flick response (TF) elicited by noxious heat (Fields et al., 1983a). We now report that neurons in the PAG region also show changes in activity related to TF.

Extracellular recordings were made from the PAG and the ventrally adjacent tegmentum at sites from which it was possible to inhibit TF using stimulating currents of $10 \mu \mathrm{A}$ or less. Cell activity, time of TF occurrence, and tail temperature were recorded during 5 repetitions of the heat stimulus. Periresponse and peristimulus histograms were plotted with reference to the TF and tail temperature, respectively.

A significant number of neurons in the PAG region showed changes in activity that preceded the TF. "Midbrain On-cells" (13.6\% of the sample) displayed an abrupt increase in firing just prior to the TF. "Midbrain Off-cells" (4.4\%) paused just prior to the TF. The remaining neurons (241 of 294 , or $82 \%$ ) did not exhibit changes in firing prior to the TF.

Thus, cells with changes in activity related to the TF are present in the PAG region as well as in the RVM. The PAG has a large projection to the RVM, and microinjection of morphine in the PAG increases activity of RVM Off-cells and decreases that of RVM On-cells. Thus, it is likely that Onand Off-cells found in the midbrain participate in the welldocumented modulation of nociceptive reflexes by the PAG and that this action is mediated by TF-related neurons in the RVM.

There is a substantial body of evidence implicating neurons of the midbrain periaqueductal gray (PAG) in the modulation of pain (Mayer and Price, 1976; Fields and Basbaum, 1978; Basbaum and Fields, 1984). Electrical stimulation of the PAG in man produces analgesia (Hosobuchi et al., 1977; Richardson and Akil, 1977) and inhibits responses to noxious stimuli in rats, cats, and monkeys (Reynolds, 1969; Mayer and Liebeskind,

Received Apr. 7, 1986; revised July 11, 1986; accepted July 14, 1986.

We wish to thank Brett Williams for histology, Annettc Lowe for artwork, Ian Hentall and Don Hoffman for computer programs, and Nick Barbaro and Dave Reichling for helpful comments on the manuscript. This work was supported by grant DA 01949. M.M.H. was supported by PHS Grant 5T32 NS07067-07.

Correspondence should be addressed to Mary M. Heinricher, Department of Physiology S-762, University of California at San Francisco, San Francisco, CA 94143.

a Present address: Department of Physiology, Xian Medical College, Xian, Shaanxi, People's Republic of China.

Copyright @ 1987 Society for Neuroscience $0270-6474 / 87 / 010271-08 \$ 02.00 / 0$
1974; Oliveras et al. 1974; Lewis and Gebhart, 1977; Gebhart and Toleikis, 1978; Hayes et al., 1979). The PAG has relatively high concentrations of opiate binding sites (Atweh and Kuhar, 1977), as well as of endogenous opioid peptides (Uhl et al., 1977; Sar et al., 1978; Finley et al., 1981a; Moss et al., 1983), and direct injection of opiate agonists into the PAG suppresses behavioral and neuronal responses to noxious stimulation (Liebeskind et al., 1973; Jacquet and Lajtha, 1976; Lewis and Gebhart, 1977; Yeung et al., 1977; Yaksh and Rudy, 1978; Bennett and Mayer, 1979; Cheng et al., 1986).

One approach to the analysis of neural systems involved in pain modulation is to study the physiological properties of neurons in regions implicated in this function. However, to date, neurophysiological studies have not revealed a clear relation between the activity of PAG neurons and the inhibition of nociceptive transmission. One possible reason for this is that the neuronal population of a multifunctional structure such as the PAG is likely to be heterogeneous. PAG neurons are, in fact, morphologically diverse (Hamilton, 1973; Mantyh, 1982b; Beitz and Shepard, 1985), and immunocytochemical studies have revealed extensive chemical heterogeneity as well (Hökfelt et al., 1977; Finley et al., 1981b; Uhl and Snyder, 1981; Beitz, 1982b; Moss et al., 1983). Under such circumstances it is particularly important to identify physiological criteria that can be used to associate individual neurons with a specific function such as pain modulation.

Recently, work from this laboratory established a classification system for cells in the rostral ventral medulla (RVM), a region that includes the nucleus raphe magnus, nucleus reticularis gigantocellularis pars alpha, and nucleus reticularis paragigantocellularis lateralis. Like the PAG, this area is associated with modulation of nociception. Most neurons in RVM belong to 1 of 2 classes of cells whose members show abrupt changes in firing just prior to the occurrence of the tail-flick reflex (TF) evoked by noxious heat: Cells of 1 class (Off-cells) pause, and those of the other class (On-cells) accelerate, immediately before the TF (Fields et al., 1983a). For several reasons, it is likely that cells of both classes are involved in modulation of dorsal horn nociceptive processing and in opiate analgesia. Both Off- and On-cells are found in regions of the medulla having the lowest threshold for inhibition of the TF by electrical stimulation (Fields et al., 1983a), and a significant proportion of both cell classes projects to the spinal cord (Vanegas et al., 1984a). Furthermore, the activity of both On- and Off-cells is altered by systemically administered morphine given in doses sufficient to inhibit the TF: Off-cell activity is increased (Fields et al., 1983b), while that of On-cells is decreased (Barbaro et al., 1986).

The identification of these 2 classes of neurons in the RVM 


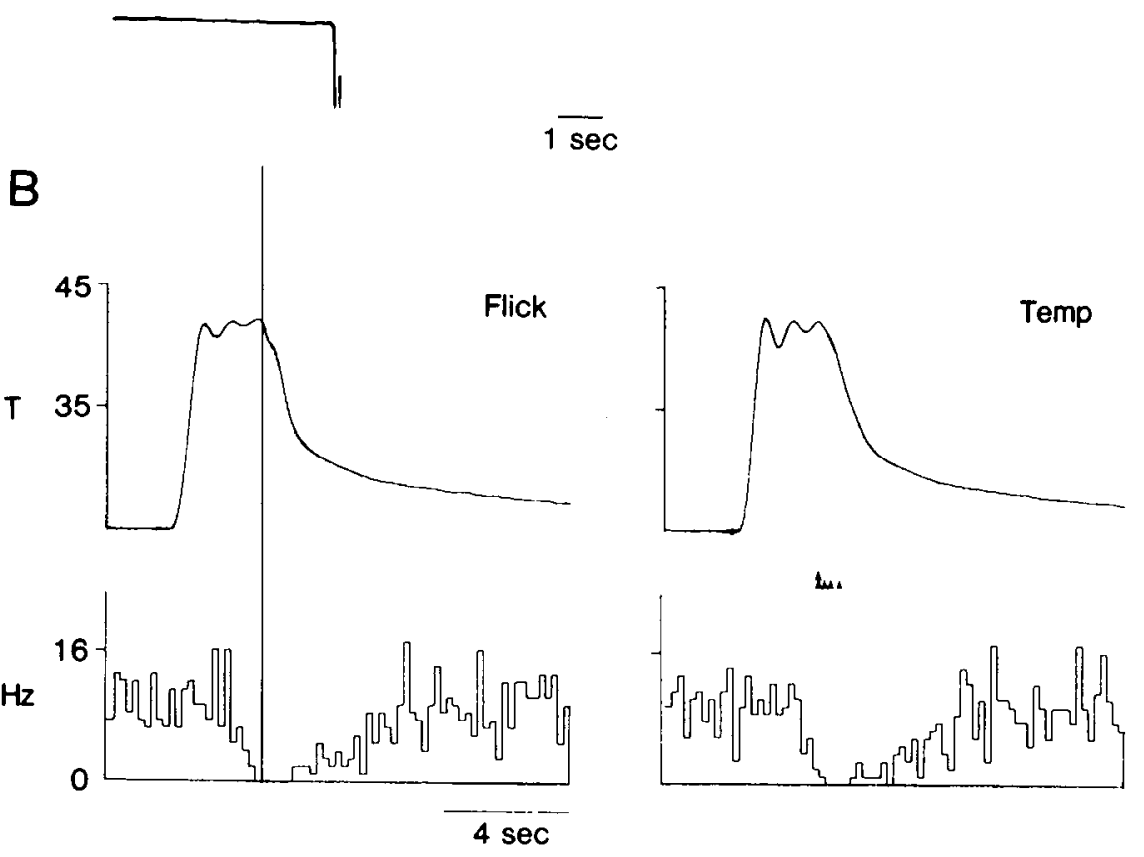

Figure 1. TF-related changes in activity of midbrain Off-cell. $A$, Single oscilloscope sweep shows pause in cell activity (upper trace) just before TF (lower trace indicates tail movement). Sweep length, 10 sec. $B$, Response of same Offcell averaged over 5 TF trials. The cell shows the typical Off-cell pause beginning just prior to the TF. In both left and right histograms, upper trace is tail temperature $\left(T,{ }^{\circ} \mathrm{C}\right)$ and lower trace is cell activity $(\mathrm{Hz})$. Left, Tail temperature and cell activity are aligned with occurrence of the TF (vertical line). Right, Same data as at left aligned with reference to tail temperature. Triangles indicate the occurrence of the TF on individual trials.

$4 \mathrm{sec}$

suggests that a similar physiological approach would be of value in the analysis of properties of PAG neurons. Several lines of evidence indicate a close functional relationship between the neurons of the RVM and those of the PAG. First, anatomical studies reveal a heavy projection from the PAG (particularly its dorsal and ventrolateral aspects) to the RVM, as well as a projection from the RVM to the PAG (Gallagher and Pert, 1978; Abols and Basbaum, 1981; Beitz, 1982a; Mantyh, 1982a; Carlton et al., 1983). Second, activation of PAG neurons, either by electrical stimulation or by microinjection of the potent neuroexcitant glutamate, has an excitatory effect on neurons in RVM (Fields and Anderson, 1978; Behbehani and Fields, 1979; Pomeroy and Behbehani, 1979; Mohrland and Gebhart, 1980; Vanegas et al., 1984b; Willis et al., 1984). Microinjection of opiates in the PAG also alters the activity of RVM neurons (Behbehani and Pomeroy, 1978; Mohrland and Gebhart, 1980; Cheng et al., 1986). Although the effects of RVM stimulation on neurons in the PAG have not been studied systematically, some PAG neurons are excited by RVM stimulation (Shah and Dostrovsky, 1980). Finally, lesion studies demonstrate that the RVM plays a major role in the antinociceptive actions of the PAG. Large electrolytic lesions of the RVM block the analgesia produced in behaving animals by electrical stimulation and microinjection of morphine in the PAG (Prieto et al., 1983; Young et al., 1984). In anesthetized rats, bilateral lesions of RVM or blockade by lidocaine microinjection antagonize the inhibition by PAG stimulation of both spinally mcdiatcd reflexes (Sandkühler and Gebhart, 1984; Lovick, 1985) and dorsal horn neurons (Gebhart et al., 1983).

Thus, the important functional relationship between the PAG and the RVM raises the possibility that cells with properties similar to those of RVM On- and Off-cells would be found in the PAG. The aim of the present study was to determine if such cells would be found in the lightly anesthetized rat. We now report that, as in the RVM, 2 classes of cells showing abrupt changes in activity immediately prior to the TF are present in the PAG. Midbrain Off-cells pause and midbrain On-cells accelerate just before the occurrence of the TF. A preliminary account of this work has been presented (Heinricher et al., 1985).

\section{Materials and Methods}

Male Sprague-Dawley rats (250-325 g) were initially anesthetized with pentobarbital $(55 \mathrm{mg} / \mathrm{kg}$, i.p.). A catheter was inserted in an external jugular vein, and the animals were placed in a stereotaxic apparatus. A small craniectomy was made to allow access to the midbrain for stimulation and recording. Body temperature was maintained at approximately $38^{\circ} \mathrm{C}$ using a circulating water pad.

Following surgery, animals were allowed to recover from the initial anesthetic dose to the point that a TF response could be elicited by noxious heating of the tail. The animals were then maintained in a lightly anesthetized state by a continuous infusion of methohexital at a level $(15-30 \mathrm{mg} / \mathrm{kg} / \mathrm{hr})$ that permitted a stable baseline TF latency of 4-5 sec but that was sufficient to prevent signs of discomfort. The animals did not move spontaneously, nor did they show prolonged withdrawal responses to noxious paw pinch.

The methods for eliciting and recording the TF were as follows. A projector lamp was focused on the blackened ventral surface of the tail. A thermistor probe placed in contact with the tail provided a signal for feedback control of the heat stimulus, which was adjusted at the beginning of cach experiment to the lowest level that elicited a TF with a latency of 4-5 sec from heat onset. This usually required a tail temperature of $42-45^{\circ} \mathrm{C}$, although lower levels were sometimes sufficient. If no TF occurred, the heat was always turned off at $10 \mathrm{sec}$. The tail was attached to a mechanoelectric bridge transducer so that the TF latency could be recorded.

A gold- and platinum-plated monopolar stainless steel electrode, stereotactically placed in the midbrain approximately $1 \mathrm{~mm}$ dorsal to the dorsal border of the PAG, was used for monopolar stimulation and for extracellular recording. The electrode was connected to a stimulator 


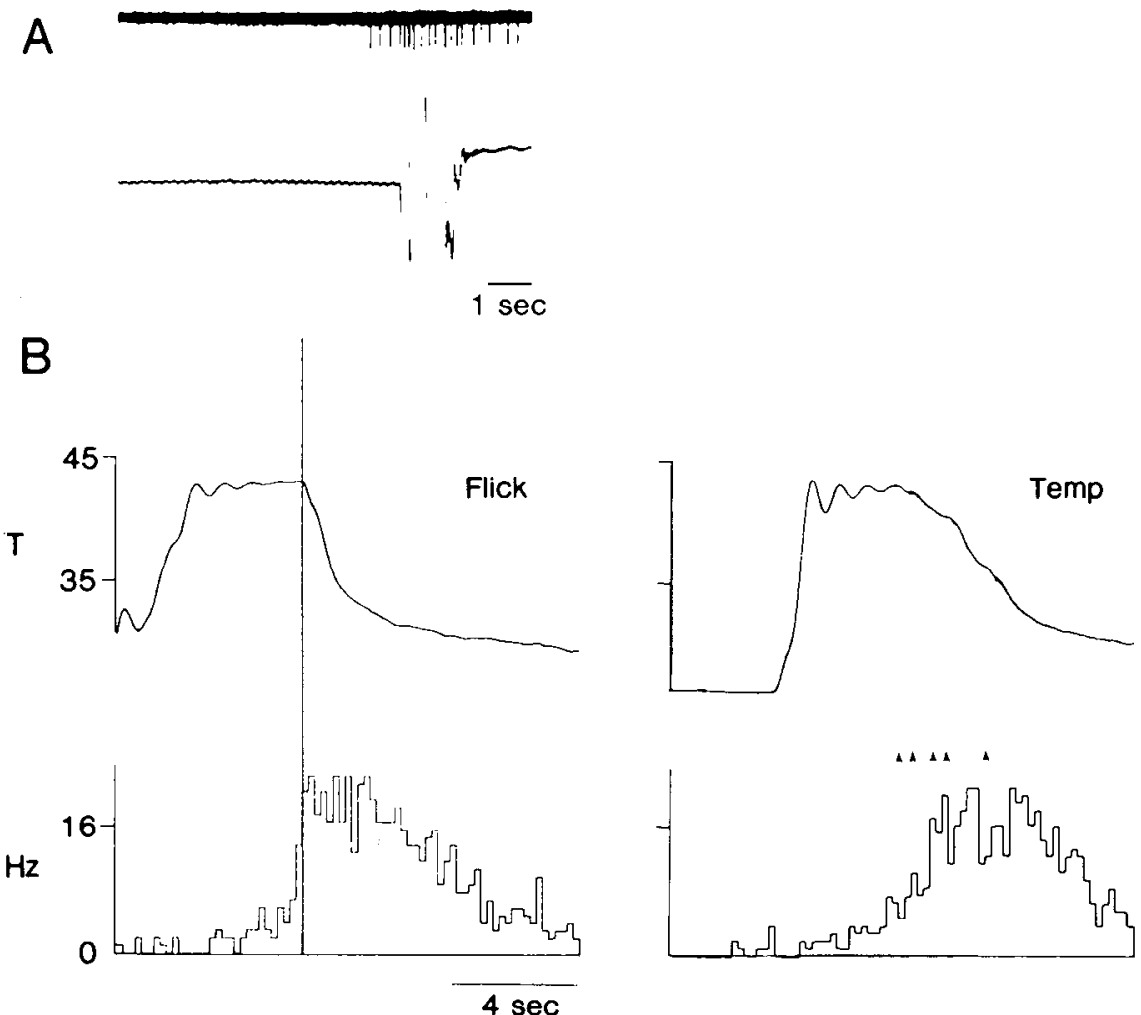

Figure 2. TF-related changes in activity of midbrain On-cell. This cell displays the typical On-cell burst that begins just prior to the TF and continues for more than $10 \mathrm{sec}$. $A$, Single oscilloscope sweep shows acceleration (upper trace) just before TF (lower trace indicates tail movement). Sweep length, $10 \mathrm{sec}$. $B$, Response of same On-cell averaged over 5 TF trials. In both left and right histograms, upper trace is tail temperature $\left(T,{ }^{\circ} \mathrm{C}\right)$ and lower trace is cell activity $(\mathrm{Hz})$. Left. Tail temperature and cell activity are aligned with occurrence of the TF (vertical line). Right, Same data as at left aligned with reference to tail temperature. Triangles indicate the occurrence of the TF on individual trials. The increase in cell activity is more abrupt when aligned with the occurrence of the TF than when aligned with tail temperature.

and advanced in $200 \mu \mathrm{m}$ steps until a site was reached at which stimulation with currents of no more than $10 \mu \mathrm{A}(400 \mu \mathrm{sec}$ cathodal pulses, $50 \mathrm{~Hz}$ continuous trains begun $3 \mathrm{sec}$ prior to the heat stimulus) resulted in inhibition of the TF (using the 10 sec cut-off). A TF occurred almost immediately after termination of this electrical stimulation. The electrode was then connected to the amplifier for extracellular recording. Action potentials were amplified, filtered, and converted to voltage pulses using a window discriminator. The shape of the action potential was continuously monitored on an oscilloscope, and pulses were integrated and displayed on a strip-chart recorder. Within each penetration, the search for units was discontinued at a point approximately $1 \mathrm{~mm}$ ventral to the ventral border of the PAG (determined stereotactically).

The electrode was advanced at a slow step rate $(1 \mu \mathrm{m} / \mathrm{sec})$ until a unit was encountered. The majority of cells were located by observation of spontaneous activity; however, noxious pinch of a paw delivered approximately once in each $100 \mu \mathrm{m}$ advance of the microelectrode was used as a search stimulus. Each cell's responses to noxious pinch and to non-noxious cutaneous stimuli (brisk brush, tap) were determined, and it was then characterized according to the classification system applied to cells of the RVM by Fields et al. (1983a). Cell activity, time of TF occurrence, and tail temperature were stored (Data General Nova 2) during 5 repetitions of the heat stimulus. Periresponse and peristimulus histograms were then plotted with reference to the occurrence of the $\mathrm{TF}$ and tail temperature, respectively.

At the completion of the experiment, a lesion was made at a site of interest (20 $\mu \mathrm{A} \mathrm{DC}$ anodal current, $10 \mathrm{sec})$. The animal was perfused intracardially with $0.9 \%$ saline followed by $10 \%$ formalin. All lesion sites were located in cresyl violet-stained coronal sections according to the atlas of Pellegrino et al. (1979).

\section{Results}

A total of 294 cells in the PAG and ventrally adjacent tegmentum was studied in 37 experiments. Spike polarity was typically negative-positive, and spike amplitude was $100-200 \mu \mathrm{V}$.

\section{Midbrain Off-cells}

Thirteen cells ( $4.4 \%$ of the sample) showed a decrease in cell activity just prior to the occurrence of the TF (Fig. 1). The delay between the cessation of midbrain Off-cell activity and the TF ranged from approximately 0.2 to $1 \mathrm{sec}$, and the duration of the TF-related pause in activity varied from $0.8 \mathrm{sec}$ to more than $10 \mathrm{sec}$.

Noxious pinch inhibited the discharge of all 13 midbrain Offcells. The inhibition could be elicited from large areas of the body, usually encompassing all 4 limbs, the tail, and face. Two cells were also inhibited by brisk brushing or tap over the same area.

\section{Midbrain On-cells}

Forty cells (13.6\% of the sample) showed an increase in firing that preceded the TF by an interval ranging from 0.2 to $2 \mathrm{sec}$ for different cells (Fig. 2). The duration of the TF-related acceleration was also highly variable, with some neurons showing a burst lasting less than $0.5 \mathrm{sec}$ (and consisting of no more than 10 spikes), while others continued firing at a high rate for 10 or more sec following the TF.

All midbrain On-cells were excited by noxious pinch over large areas of the body, and 10 were also excited, although to a lesser degree, by brisk brushing or tapping over the same region.

\section{Cells that showed no activity change prior to $T F$}

The great majority of cells examined ( 241 of $294 ; 82 \%$ ) did not exhibit changes in firing before TF. No discernible cutaneous receptive field could be identified for 211 of these cells. Of the remaining 30 neurons, 21 were excited and 4 inhibited exclusively by noxious pinch. Three were excited by pinch and by tapping or light brush; 2 were excited solely by tapping.

The discharge of 9 units increased just after the TF, the delay between the TF and the first spike in this burst ranging from 0.6 to 2 sec. In these cases, the TF-related activity usually con- 


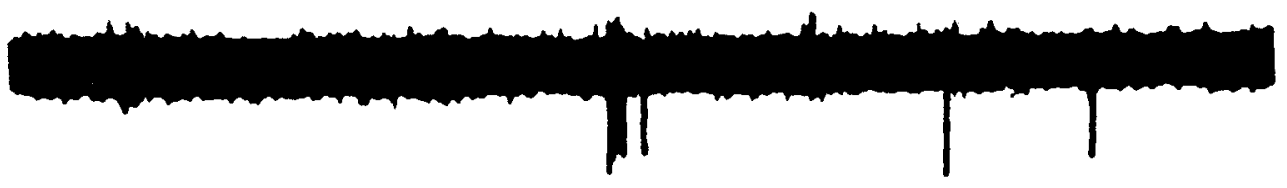

Figure 3. Increase in cell activity that did not begin until approximately $1 \mathrm{sec}$ after the TF. Single oscilloscope trace; calibration bar, 1 sec. Upper trace is cell activity; lower trace indicates tail movement.

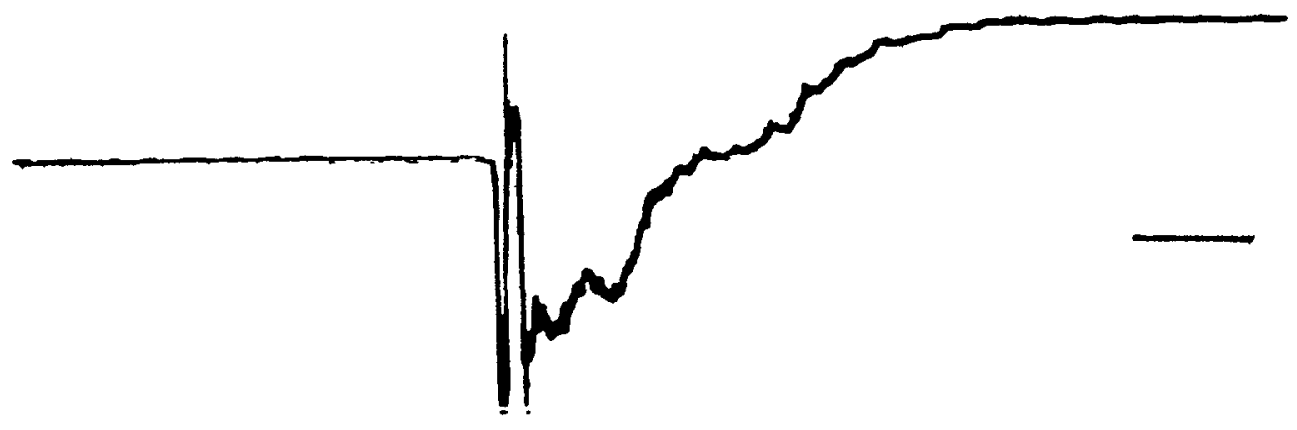

sisted of only 3-10 spikes. An example of such a cell is shown in Figure 3.

\section{Pattern of spontaneous discharge}

Generally, spontaneous firing rates were low. The mean rate for the entire sample was $5.28 \pm 0.72$ spikes $/ \mathrm{sec}$. Over half of the cells (57.4\%) fired irregularly at less than 2 spikes/sec, and $6.7 \%$ of the sample had no activity in the absence of cutaneous stimulation. A small number of cells did, however, show relatively high levels of spontaneous discharge, with $7.6 \%$ of the neurons discharging at rates between 20 and 40 spikes/sec. Mean discharge rates of midbrain On- and Off-cells and cells without TF-related activity were not significantly different (1-way ANOVA, $p>0.05$ ). Many TF-related neurons displayed a pattern of firing in which periods of silence lasting as long as several minutes alternated with periods of irregular spontaneous activity of similar duration. A similar periodicity of firing under light barbiturate anesthesia has been reported for On- and Off-cells in the RVM (Barbaro et al., 1985).

Cells without TF-related changes in activity did not show periodic fluctuations in firing. Spontaneous activity of these cells was either regular or, more commonly, irregular, without clear silent and active periods.

\section{Locations of midbrain neurons}

All recording was in regions from which it was possible to inhibit the TF using stimulation currents of no more than $10 \mu \mathrm{A}$. Recording was often initiated near the dorsal border of the PAG, but in many cases, inhibition of the TF was first obtained near the level of the cerebral aqueduct.

Cells were encountered mainly in the dorsolateral and ventrolateral PAG (as defined by Beitz, 1985) and in the midbrain tegmentum immediately ventral to the PAG, even though several of the electrode penetrations sampled the region dorsal to the dorsal margin of the cerebral aqueduct. The locations of midbrain On- and Off-cells are shown in Figure 4 and those of cells whose activity did not change prior to the TF in Figure 5. More cells were found ventral than dorsal to the level of the cerebral aqueduct. The midbrain Off-cells identified in these experiments were primarily in the ventrolateral PAG, and all were at or ventral to the level of the aqueduct. The distribution of midbrain On-cells was less restricted, but such cells were more often found ventral to the level of the aqueduct. Cells without TF-related activity were scattered throughout the region searched.

\section{Discussion}

These observations demonstrate the existence of 2 populations of neurons in the PAG that exhibit changes in activity related to the occurrence of a spinally mediated nociceptive reflex. Firing of midbrain Off-cells decreases and that of midbrain Oncells increases just prior to the TF response elicited by noxious heat.

With 1 exception, previous studies of the cutaneous response properties of PAG neurons did not attempt to relate changes in cell activity to behavior. Sakuma and Pfaff (1980), recording in urethane-anesthetized rats, studied PAG neurons that were antidromically activated from the nucleus reticularis gigantocellularis of the medullary reticular formation. They reported that only a small number of cells (11\%) was excited by firm pressure over the hindquarter region, and none responded to noxious pinch. In the barbiturate-anesthetized cat, Nakahama et al. (1981) observed that more than half of their sample responded to both noxious and non-noxious cutaneous stimuli. Twenty percent were maximally excited by non-noxious stimulation, and none responded exclusively to noxious stimuli. The findings of Eickhoff et al. (1978) in the chloralose-anesthetized rat were similar. They studied neurons in the PAG and adjacent reticular formation that were responsive to electrical stimulation of the coccygeal nerve. Almost half (42\%) of the units tested were excited by non-noxious tactile stimulation, and $22 \%$ were excited by both non-noxious stimuli and by noxious pinch. Only $13 \%$ of the cells were driven solely by noxious stimulation. In contrast, Sanders et al. (1980), using the same preparation and search stimulus, found that a high percentage (48\%) of their sample was activated by noxious radiant heat and that an additional $25 \%$ was inhibited by such stimulation. Significantly, they reported that cell firing was not a linear function of tail temperature. Rather, there was a sudden increase in firing rate when the temperature reached noxious levels.

In a series of experiments similar to those reported here, Handwerker and Sack (1982) used awake, restrained rats in an attempt to correlate activity of PAG neurons with the occurrence of the TF reflex. Twenty-seven neurons in the PAG and adjacent 


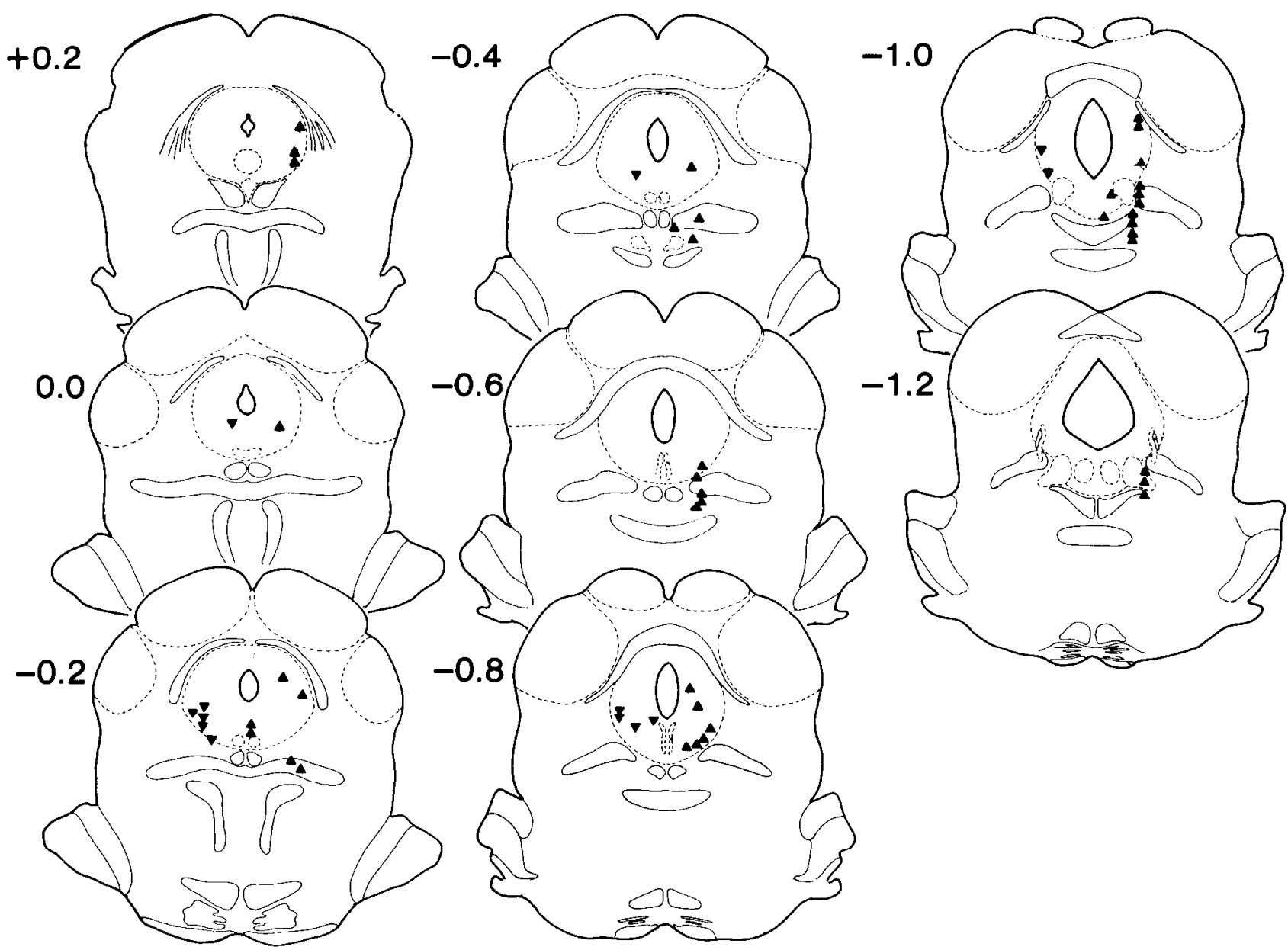

Figure 4. Drawings of representative coronal sections through the midbrain showing locations of 13 Off-cells (downward pointing arrows, left) and 40 On-cells (upward pointing arrows, right). Anterior-posterior, +0.2 to $-1.2 \mathrm{~mm}$ (atlas of Pellegrino et al., 1979).

reticular formation that responded to electrical stimulation of the coccygeal nerve were studied. More than half (52\%) showed no change in firing related to the TF. The firing of 10 cells increased and that of 3 decreased prior to the TF. These 2 groups of cells may correspond to the midbrain On-cell (13.6\% of our sample of 294 neurons) and Off-cell (4.4\% of our sample) classes we have described. There are, however, some differences between their results and ours. First, the changes in firing they described were more gradual and preceded the TF by as much as $6 \mathrm{sec}$. In addition, many cells showed a post-TF change in firing that was in a direction opposite to that preceding the TF. In contrast, the alterations in firing we observed were unidirectional, preceded the TF by no more than 2 scc, and wcrc maintained for up to several minutes after the TF. We did not observe biphasic changes in cell firing. Such differences in the time course of TF-related changes in cell activity may be due to our use of barbiturate anesthesia.

A differential distribution of the physiologically characterized cell classes was found with our search methods. Neurons without TF-related activity were distributed throughout the region sampled. The locations of midbrain On-cells were similar to those of cells without TF-related activity in that they were also scattered throughout the dorsolateral and ventrolateral PAG and in the midbrain tegmentum ventral to the PAG. Midbrain Offcells were only found ventral to the level of the cerebral aque- duct, most frequently in the ventrolateral subdivision. No Offcells were found ventral to the PAG itself. This restricted distribution of midbrain Off-cells is of particular significance for 2 reasons. First, the ventrolateral subdivision is often reported to be the most sensitive PAG site for stimulation- or opiate-induced antinociception (Jacquet and Lajtha, 1976; Lewis and Gebhart, 1977; Yeung et al., 1977). In addition, this area of the PAG gives rise to the major projection to the RVM (Gallagher and Pert, 1978; Abols and Basbaum, 1981; Beitz, 1982b; Carlton et al., 1983). Since there is convincing evidence that the antinociceptive effect of PAG stimulation is primarily a consequence of activation of neurons projecting to the RVM (Fields and Basbaum, 1976; Vanegas et al., 1984b), the distribution of midbrain Off-cells is consistent with a particularly important role for this cell class in mediating the descending influence of the PAG on medullary pain modulating neurons.

The presence of numerous PAG neurons that do not show TF-related activity distinguishes this region from the RVM, where the majority of cells studied exhibited TF-related changes in activity (Fields et al., 1983a; Barbaro et al., 1986). Although a role for these neurons in pain modulation should not be ruled out, it is also possible that they are involved in one or more of the many functions that have been attributed to the PAG. These include control of lordosis (Sakuma and Pfaff, 1979) and gut motility (Skultety, 1959), "visceral alerting" and rage (Hun- 


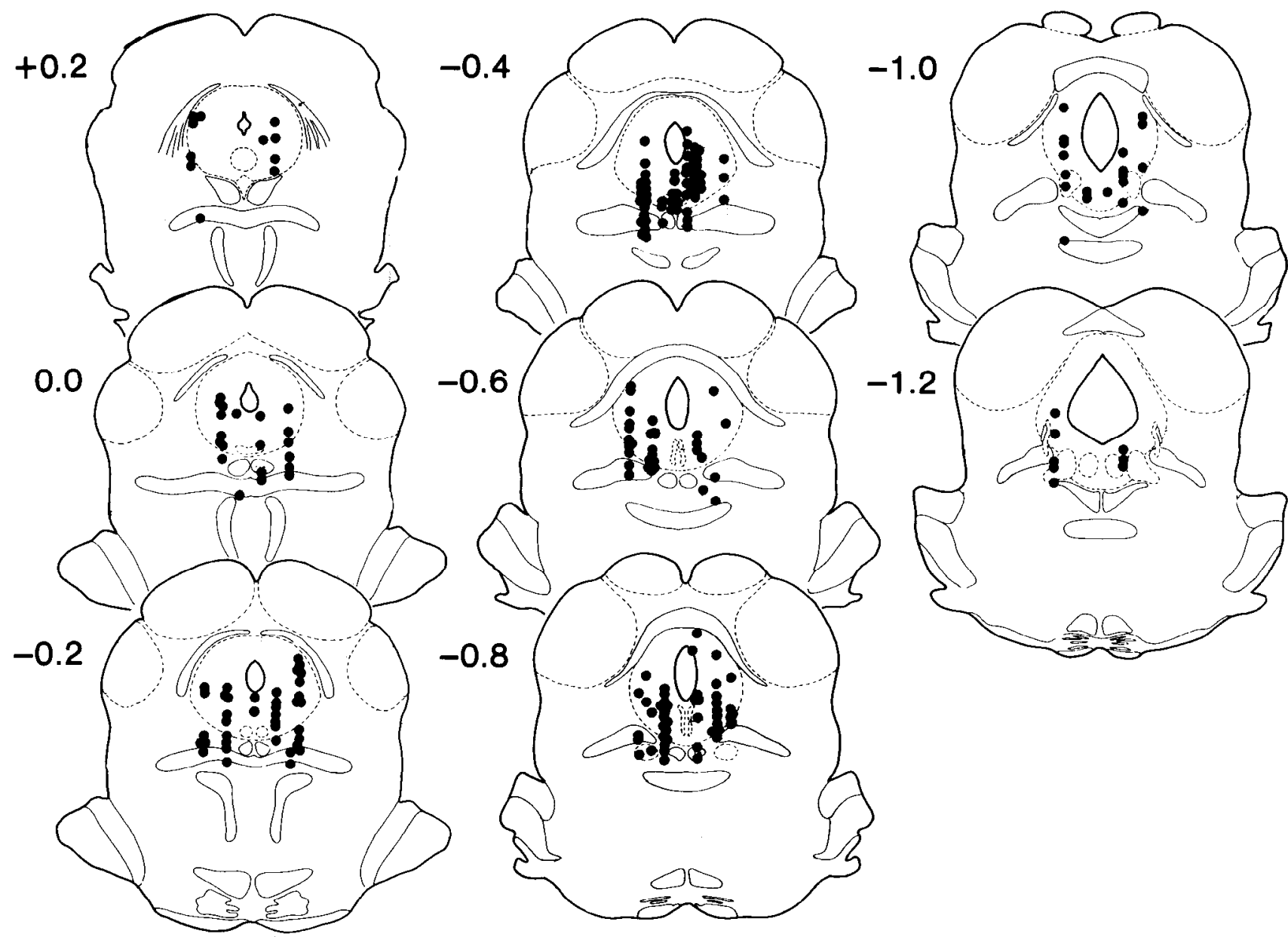

Figure 5. Drawings of representative coronal sections through the midbrain showing locations of 241 cells that did not exhibit TF-related activity. Sections as in Figure 4.

sperger, 1956; Lovick, 1985), and vocalization (Waldbillig, 1975; Jurgens and Pratt, 1979).

It is important to consider whether the cells studied in the present experiments constitute a representative sample of the PAG cell population, as there are several possible sources of sampling error. First, extracellular recording techniques are unavoidably biased towards selection of larger neurons. Thus, if there were systematic differences in soma size among the different classes, the relative numbers of On- and Off-cells and cells without TF-related activity identified would be affected. Also, the larger number of cells encountered in more lateral regions could reflect the fact that cell size in the PAG increases with distance from the aqueduct (Mantyh, 1982b). Another concern relates to the fact that many neurons had very low rates of spontaneous discharge, which would tend to favor observations of increases and obscure any decreases in firing associated with the TF. This would reduce the number of Off-cells encountered, as would the use of noxious pinch as a search stimulus. Finally, the use of barbiturate anesthesia could affect the characteristics of the cells recorded.

It is not clear whether the midbrain On- and Off-cells described in this paper are functionally linked to cells in the RVM with similar physiological properties. Under our experimental conditions, the midbrain TF-related neurons constitute only a fraction of the total cell sample, and it is not known whether they project to RVM. Nevertheless, we feel that it is a reasonable possibility that On- and Off-cells in the midbrain act as a functional unit with On- and Off-cells in the medulla to modulate nociceptive transmission. Thus, Vanegas et al. (1984b) have shown that electrical stimulation in the PAG excites both Offand On-cells in the RVM at current thresholds indistinguishable from those required for inhibition of the TF. Moreover, morphine microinjection in the PAG alters activity of RVM Onand Off-cells but has no effect on cells without TF-related changes in activity. In contrast with the effects of electrical stimulation, microinjection of morphine in the PAG differentially affects the activity of RVM On- and Off-cells. Spontaneous activity of Offcells is increased and that of On-cells is decreased (Cheng et al., 1986). The disparity between the effects of electrical stimulation and morphine microinjection could be explained if there were 2 populations of opiate-sensitive neurons in the PAG that are excitatory to RVM On- and Off-cells, respectively. Presumably, only one of these hypothetical populations would be activated by opiate microinjection, although both would necessarily be excited by electrical stimulation. Since, in the RVM, only Onand Off-cells are affected by opiate administration (whether systemic or microinjected into the PAG), it is tempting to speculate that a similar situation holds in the midbrain, and that the midbrain On- and Off-cell classes we have described are the midbrain cell populations that respond to opiates. If this were 
the case, opiate microinjection in the PAG could activate RVM Off-cells via activation of midbrain Off-cells. Similarly, the suppression of RVM On-cells that results from opiate microinjection in the PAG could be a consequence of reduced excitation from midbrain On-cells.

In summary, several converging lines of evidence support the notion that the PAG and RVM are major supraspinal components of a distributed, highly interconnected neural network that modulates transmission of nociceptive information at the spinal and medullary dorsal horn (Fields and Heinricher, 1985). Our demonstration of neurons in both the PAG and the RVM that show abrupt changes in discharge immediately preceding the occurrence of a nociceptive reflex provides additional support for this proposal.

\section{References}

Abols, I., and A. Basbaum (1981) Afferent connections of the rostral medulla of the cat: A neural substrate for midbrain-medullary interactions in the modulation of pain. J. Comp. Neurol. 201: 285-297.

Atweh, S., and M. Kuhar (1977) Autoradiographic localization of opiate receptors in rat brain. II. The brain stem. Brain Res. 129:112.

Barbaro, N., H. Fields, and M. Heinricher (1985) Reciprocal activity in on- and off-cells in the rostral ventromedial medulla of the rat. Soc. Neurosci. Abstr. 11: 1180.

Barbaro, N., M. Heinricher, and H. Fields (1986) Putative pain modulating neurons in the rostral ventral medulla: Reflex-related activity predicts effects of morphine. Brain Res. 366: 203-210.

Basbaum, A., and H. Fields (1984) Endogenous pain control systems: Brainstem spinal pathways and endorphin circuitry. Annu. Rev. Neurosci. 7: 309-338.

Behbehani, M., and H. Fields (1979) Evidence that an excitatory connection between the periaqueductal gray and nucleus raphe magnus mediates stimulation produced analgesia. Brain Res. 170: 85-93.

Behbehani, M., and S. Pomeroy (1978) Effect of morphine injected in periaqueductal gray on the activity of single units in nucleus raphe magnus of the rat. Brain Res. 149: 266-269.

Beitz, A. (1982a) The organization of afferent projections to the midbrain periaqueductal gray of the rat. Neuroscience 7: 133-159.

Beitz, A. (1982b) The nuclei of origin of brain stem enkephalin and substance $\mathbf{P}$ projections to the rodent nucleus raphe magnus. Neuroscience $7: 2753-2768$.

Beitz, A. J. (1985) The midbrain periaqueductal gray in the rat. I. Nuclear volume, cell number, density, orientation, and region subdivisions. J. Comp. Neurol. 237: 445-459.

Beitz, A. J., and R. D. Shepard (1985) The midbrain periaqueductal gray in the rat. II. A Golgi analysis. J. Comp. Neurol. 237: 460-475.

Bennett, G., and D. Mayer (1979) Inhibition of spinal cord interneurons by narcotic microinjection and focal electrical stimulation in the periaqueductal gray matter. Brain Res. 172: 243-257.

Carlton, S., G. Leichnetz, E. Young, and D. Mayer (1983) Supramedullary afferents of the nucleus raphe magnus in the rat: A study using the transcannula HRP gel and autoradiographic technique. J. Comp. Neurol. 214: 43-58.

Cheng, Z.-F., H. Fields, and M. Heinricher (1986) Morphine microinjected into the periaqueductal gray has differential effects on 3 classes of medullary neurons. Brain Res. 375: 57-65.

Eickhoff, R., H. Handwerker, D. McQueen, and E. Schick (1978) Noxious and tactile input to medial structures of midbrain and pons in the rat. Pain 5: 99-113.

Fields, H., and S. Anderson (1978) Evidence that raphe-spinal neurons mediate opiate and midbrain stimulation-produced analgesias. Pain 5: 333-349.

Fields, H., and A. Basbaum (1978) Brainstem control of spinal pain transmission neurons. Annu. Rev. Physiol. 40: 217-248.

Fields, $H$., and M. Heinricher (1985) Anatomy and physiology of a nociceptive modulatory system. Phil. Trans. R. Soc. London [Biol.] 308: 361-374.

Fields, H., J. Bry, I. Hentall, and G. Zorman (1983a) The activity of neurons in the rostral medulla of the rat during withdrawal from noxious heat. J. Ncurosci. 3: 545-552.
Fields, H., H. Vanegas, I. Hentall, and G. Zorman (1983b) Evidence that disinhibition of brain stem neurones contributes to morphine analgesia. Nature 306: 684-686.

Finley, J., J. Maderdrut, and P. Petrusz (1981a) The immunocytochemical localization of enkephalin in the central nervous system of the rat. J. Comp. Neurol. 198: 541-565.

Finley, J., J. Maderdrut, L. Roger, and P. Petrusz (1981b) The immunocytochemical localization of somatostatin-containing neurons in the rat central nervous system. Neuroscience 6: 2173-2192.

Gallagher, D., and A. Pert (1978) Afferents to brain stem nuclei (brain stem raphe, nucleus reticularis pontis caudalis and nucleus gigantocellularis) in the rat as demonstrated by microiontophoretically applied horseradish peroxidase. Brain Res. 144: 257-275

Gebhart, G., and J. Toleikis (1978) An evaluation of stimulationproduced analgesia in the cat. Exp. Neurol. 62: 570-579.

Gebhart, G., J. Sandkühler, J. Thalhammer, and M. Zimmermann (1983) Inhibition of spinal nociceptive information by stimulation in midbrain of the cat is blocked by lidocaine microinjected in nucleus raphe magnus and medullary reticular formation. J. Neurophysiol. 50: $1446-1459$.

Hamilton, B. (1973) Cytoarchitectural subdivisions of the periaqueductal gray matter of the cat. J. Comp. Neurol. 149: 149-154.

Handwerker, H., and R. Sack (1982) Single unit activity in the rat's midbrain during nociceptive tail flick reaction. Neurosci. Lett. 30: $79-84$.

Hayes, R., D. Price, M. Ruda, and R. Dubner (1979) Suppression of nociceptive responses in the primate by electrical stimulation of the brain or morphine administration: Behavioral and electrophysiological comparisons. Brain Res. 167: 417-421

Heinricher, M., Z.-F. Cheng, and H. Fields (1985) Activity of neurons in the periaqueductal gray during withdrawal from noxious heat. Soc. Neurosci. Abstr. 11: 1178.

Hökfelt, T., A. Ljungdahl, L. Terenius, R. Elde, and G. Nilsson (1977) Immunohistochemical analysis of peptide pathways possibly related to pain and analgesia: Enkephalin and substance P. Proc. Natl. Acad. Sci. USA 74: 3081-3085.

Hosobuchi, Y., J. Adams, and R. Linchitz (1977) Pain relief by electrical stimulation of the central gray matter in humans and its reversal by naloxone. Science 197: 183-186.

Hunsperger, R. (1956) Role of substantia grisea centralis mesencephali in electrically induced rage reactions. Prog. Neurobiol. (NY) 1: 289294.

Jacquet, U., and A. Lajtha (1976) The periaqueductal gray: Site of morphine analgesia and tolerance as shown by 2 -way cross tolerance between systemic and intracerebral injections. Brain Res. 103: 501513.

Jurgens, U., and R. Pratt (1979) Role of the periaqueductal grey in vocal expression of emotion. Brain Res. 167: 367-378.

Lewis, V., and G. Gebhart (1977) Morphine-induced and stimulationproduced analgesias at coincident periaqueductal central gray loci: Evaluation of analgesic congruence, tolerance and cross tolerance. Exp. Neurol. 57: 934-955.

Liebeskind, J., G. Guilbaud, J. Besson, and J. Oliveras (1973) Analgesia from electrical stimulation of the periaqueductal gray matter in the cat: Behavioral observations and inhibitory effects on spinal cord interneurons. Brain Res. 50: 441-446.

Lovick, T. (1985) Ventrolateral medullary lesions block the antinociceptive and cardiovascular responses elicited by stimulating the dorsal periaqueductal grey matter in rats. Pain $21: 241-252$.

Mantyh, P. (1982a) The ascending input to the midbrain periaqueductal gray of the primate. J. Comp. Neurol. 211: 50-64.

Mantyh, P. (1982b) The midbrain periaqueductal gray in the rat, cat, and monkey: A Nissl, Weil and Golgi analysis. J. Comp. Neurol. 204: 349-363.

Mayer, D., and J. Liebeskind (1974) Pain reduction by focal electrical stimulation in the brain: An anatomical and behavioral analysis. Brain Res. 68: 73-93.

Mayer, D., and D. Price (1976) Central nervous system mechanisms of analgesia. Pain 2: 79-404.

Mohrland, J., and G. Gebhart (1980) Effects of focal electrical stimulation and morphine microinjection in the periaqueductal gray of the rat mesencephalon on neuronal activity in the medullary reticular formation. Brain Res. 201: 23-37.

Moss, M., E. Glazer, and A. Basbaum (1983) The peptidergic organization of the cat periaqueductal gray. I. The distribution of im- 
munoreactive enkephalin-containing neurons and terminals. J. Neurosci. 3: 603-616.

Nakahama, H., K. Shima, K. Aya, and H. Fujii (1981) Peripheral somatic activation and spontaneous firing patterns of neurons in the periaqueductal gray of the cat. Neurosci. Lett. 25: 43-46.

Oliveras, J., J. Besson, G. Guilbaud, and J. Liebeskind (1974) Behavioral and electrophysiological evidence of pain inhibition from midbrain stimulation in the cat. Brain Res. 20: 32-45.

Pellegrino, L., A. Pellegrino, and A. Cushman (1979) A Stereotaxic Atlas of the Rat Brain, Plenum, New York.

Pomeroy, S., and M. Behbehani (1979) Physiologic evidence for a projection from periaqueductal gray to nucleus raphe magnus in the rat. Brain Res. 76: 143-147.

Prieto, G., T. Cannon, and J. Liebeskind (1983) N. raphe magnus lesions disrupt stimulation-produced analgesia from ventral but not dorsal midbrain areas in the rat. Brain Res. 261: 53-57.

Reynolds, D. (1969) Surgery in the rat during electrical analgesia induced by focal brain stimulation. Science 164: 444-445.

Richardson, D., and II. Akil (1977) Pain reduction by electrical brain stimulation in man. J. Neurosurg. 7: 78-183.

Sakuma, Y., and D. Pfaff (1979) Mesencephalic mechanisms for integration of female reproductive behavior in the rat. Am. J. Physiol. 237: R285-R290.

Sakuma, Y., and D. Pfaff (1980) Cells of origin of medullary projections in central gray of rat mesencephalon. J. Neurophysiol. 44:10021011.

Sanders, K., C. Klein, T. Mayer, C. Heym, and H. Handwerker (1980) Differential effects of noxious and non-noxious input on neurones according to location in ventral periaqueductal grey or dorsal raphe nucleus. Brain Res. 86: 83-97.

Sandkühler, J., and G. Gebhart (1984) Relative contributions of the nucleus raphe magnus and adjacent medullary reticular formation to the inhibition by stimulation in the periaqueductal gray of a spinal nociceptive reflex in the pentobarbital-anesthetized rat. Brain Res. 305: 77-87.

Sar, M., W. Stumpf, R. Miller, K.-J. Chang, and R. Cuatrecasas (1978)
Immunohistochemical localization of enkephalin in rat brain and spinal cord. J. Comp. Neurol. 182: 17-38.

Shah, Y., and J. Dostrovsky (1980) Electrophysiological evidence for a projection of the periaqueductal gray matter to nucleus raphe magnus in cat and rat. Brain Res. 193: 534-538.

Skultety, F. (1959) Relation of periaqueductal grey matter to stomach and bladder motility. Neurology 9: 190-197.

Uhl, G., and S. Snyder (1981) Neurotensin. In Neurosecretion and Brain Peptides, J. B. Martin, S. Reichlin, and K. L. Bick, eds., pp. 87-107, Raven, New York.

Uhl, G., R. Goodman, M. Kuhar, S. Childers, and S. Snyder (1977) Immunohistochemical mapping of enkephalin-containing cell bodies, fibers and nerve terminals in the brainstem of the rat. Brain Res. 166: 75-94.

Vanegas, H., N. Barbaro, and H. Fields (1984a) Tail-flick related activity in medullospinal neurons. Brain Res. 321: 135-141.

Vanegas, H., N. Barbaro, and H. Fields (1984b) Midbrain stimulation inhibits tail-flick only at currents sufficient to excite rostral medullary neurons. Brain Res. 321: 127-133.

Waldbillig, R. (1975) Attack, eating, drinking and gnawing elicited by electrical stimulation of rat mesencephalon and pons. J. Comp. Physiol. Psychol. 89: 212-220.

Willis, W., K. Gerhart, W. Willcockson, R. Yezierski, T. Wilcox, and C. Cargill (1984) Primate raphe- and reticulospinal neurons: Effects of stimulation in periaqueductal gray or $\mathrm{VPL}_{\mathrm{c}}$ thalamic nucleus. $\mathrm{J}$. Neurophysiol. 51: 467-480.

Yaksh, T., and T. Rudy (1978) Narcotic analgesics: CNS sites and mechanisms of action as revealed by intracerebral injection techniques. Pain 4: 229-359.

Yeung, J., T. Yaksh, and J. Rudy (1977) Mapping of brain sites for sensitivity to the direct application of morphine and focal electrical stimulation in the production of antinociception in the rat. Pain 4: 23-40.

Young, E., L. Watkins, and D. Mayer (1984) Comparison of the effects of ventral medullary lesions on systemic and microinjection morphine analgesia. Brain Res. 290: 119-129. 